\title{
Disturbances in human arm movement trajectory due to mild cerebellar dysfunction
}

\author{
S H Brown, H Hefter, $M$ Mertens, H -J Freund
}

\begin{abstract}
The temporal structure of arm movements was studied in nine cerebellar patients with mild impairment of the upper limbs and in six agematched control subjects. The experimental paradigm consisted of visually guided, step tracking movements about the elbow. Movements ranged from $10^{\circ}$ to $70^{\circ}$ in amplitude and were made under different instructions (fast, fast/accurate, accurate). As in hormal subjects, cerebellar patients were able to scale peak velocity with movement amplitude. This relationship was highly linear under all instruction conditions. Similar relationships existed between movement duration and amplitude. In contrast to normal subjects who produced movements with nearly symmetric velocity profiles, movements made by cerebellar patients were characterised by short acceleration and long deceleration durations. The degree of asymmetry was directly related to movement duration but was unaffected by movement peak velocity. Acceleration durations did not increase beyond $300 \mathrm{~ms}$ even in movements lasting up to 1s. These findings demonstrate that, despite little or no obvious impairment of the limb during routine examination, the temporal structure of voluntary movements in cerebellar patients is clearly disturbed. This supports the view that the production of an optimal movement trajectory is under cerebellar influence.
\end{abstract}

In his elegant treatise concerning motor deficits following gunshot wounds to the cerebellum, Holmes ${ }^{12}$ described a specific set of movement abnormalities which still provides the framework for clinical diagnosis of cerebellar dysfunction. In addition to hypotonia, tremor and ataxia, cerebellar patients often exhibit abnormalities in the rate, range, accuracy and force of goaldirected voluntary movements as well as irregularities in the performance of alternating movements. Since Holmes' pioneering work, cerebellar involvement in movement planning and execution has been the focus of considerable study. However, the precise role that the cerebellum plays in the control of voluntary movement is still unclear.

The widely accepted notion of movements being either "fast" or "slow" led Kornhuber" to suggest separate, central mechanisms responsible for each movement type. On the basis of disrupted eye movements in patients with cerebellar atrophy, Kornhuber proposed that the cerebellum was necessary in "the translation of the spatial concept of the movement... into time". While the cerebellum was considered to represent a clock mechanism involved in the timing of muscle activity producing a rapid movement, the basal ganglia were thought to act as a ramp generator for slow movements.

That the cerebellum may be preferentially involved in the generation of fast movements has been supported by both primate and clinical studies. It has been shown, for example, that cooling of the cerebellar nuclei in monkeys results in movements which exhibit more than one velocity peak during the dynamic phase, a phenonemon referred to by Brooks as "discontinuous". Such movements are typically characterised by delayed onset times, hypermetria and the presence of terminal oscillations. ${ }^{5-7}$ Similar disturbances in movement range and speed are seen in cerebellar patients performing fast tracking movements about the thumb ${ }^{8}$ and elbow ${ }^{9}$ and during rapid isometric movements of the thumb and index finger. ${ }^{10}$

It has been shown, however, that cerebellar lesions also give rise to specific deficits during the production of slow, continuous tracking movements. Errors in movement rate and amplitude results in a marked reduction in tracking accuracy and movements resemble a series of intermittent responses performed at inappropriately high velocities. ${ }^{11-13}$

Part of the difficulty in determining the precise role for the cerebellum during voluntary movement is the generalised assumption that movements can be classified as either "fast" or "slow". While such a classification is appealing in its simplicity, it is often not possible to determine the boundary between movement types on the basis of a single movement parameter. Kinematic analyses have shown that, despite large differences in speed, human arm movements share common organisational principles. Thus, for example, maximum velocity increases linearly with movement amplitude. ${ }^{14-16}$

More recently, the dynamic or temporal structure of movements has been the focus of increased attention since time-symmetric velocity profiles appear to be characteristic of many movement types which differ in amplitude, direction and speed and made 
under different load conditions. ${ }^{17-19}$ The observation that the time course during the dynamic phase of movements is preserved under different conditions has added further support to the theory that movement trajectory is the controlled variable underlying movement planning and excution. ${ }^{16} 20$

In addition to commonality of specific kinematic features, many movements share similar electromyographic activation patterns. A triphasic (agonist-antagonist-agonist) burst pattern, once thought to be characteristic of only the most rapid movements, has been described for movements of a wide range of speeds and amplitudes. ${ }^{152122}$ Furthermore, it has been recently shown that modulation of movement-related phasic EMG activity is directly related to the dynamic characteristics of the intended movement. ${ }^{23}$

Since it has been suggested that the cerebellum plays a crucial role in movement timing, , $^{3425}$ it would seem reasonable to hypothesise that generation of a common, temporal profile across different movement conditions may be under cerebellar control. Experiments were therefore designed to examine the dynamic features of single-joint, step tracking movements in patients exhibiting cerebellar symptoms. To minimise problems in determining, for example, movement end point, only patients with mild impairment of the upper extremities were selected. Unlike previous studies involving cerebellar patients, the present paradigm permitted an analysis of graded changes in movement speed. Thus, by altering amplitude and/or instruction, a broad range of velocities could be produced.

The results show that, for movements about the elbow, patients with mild cerebellar symptoms appear unable to produce time symmetric movements across a range of movement amplitudes and speeds. Thus, disturbances in the dynamic phase of voluntary movements may be present despite little or no impairment of the limb during routine clinical testing.

\section{Methods}

\section{Subjects}

Nine patients diagnosed with cerebellar disease were studied (eight male, one female, aged 37 to 63 years, mean age: 52 years). Following a complete clinical assessment, patients were selected on the basis of age, location of lesion, visual acuity and degree of upper limb impairment. Patients over the age of 65 years were excluded to avoid the possibility of age-related changes in motor performance. ${ }^{26}$ Patients suffering from demyelinating disease (for example, multiple sclerosis) or exhibiting major brainstem involvement were also excluded. All patients were ambulatory and presented only mild impairment of the upper limbs.

The clinical data are summarised in table 1. Four patients (WD, RB, KS, EH) suffered from chronic cerebellar disease of between two and five years duration. Using Harding's classification, ${ }^{27}$ these patients were diagnosed as suffering from ideopathic late onset cerebellar ataxia with patients RB and $\mathrm{KS}$ of the Marie-Foix-Alajouanine type; $\mathrm{EH}$, group $C$; and WD, probable group C. Four patients (BR, HF, KB, VR) presented acute cerebellar symptoms due to vascular injury. BR suffered from occlusion of both vertebral arteries with complex collateralisation of the right cerebellar hemisphere. HF suffered from an occlusion of the right posterior cerebellar artery. In patient $\mathrm{KB}$ an embolism of the right superior cerebellar artery was diagnosed and in VR, a large, ischaemia induced cyst located in the left cerebellar hemisphere. EZ had a solid metastasis (hypernephroma) located in the right cerebellar hemisphere. In cases where symptoms were bilateral, the dominant arm was tested. All patients gave informed consent for the procedures involved. Control studies were performed on six subjects with no known history of motor dysfunction (four male, two female, 30 to 60 years, mean age: 45 yrs).

\section{Experimental paradigm}

The experimental setup used in these studies was similar to that used in previous studies of step tracking movements about the elbow. ${ }^{15} 26$ Subjects were seated comfortably and grasped a manipulandum handle. The arm was abducted $90^{\circ}$ and supported along the entire length of the forearm. The manipulandum was pivoted beneath the elbow and moved freely in the horizontal plane.

An oscilloscope placed approximately 1 metre in front of the subject was used to display target and handle position. The target appeared as two vertical lines, $8 \mathrm{~mm}$ apart. The target switched at a regular interval (every 5s) between two fixed positions equidistant about an elbow angle of $90 \mathrm{deg}$

Table 1 Clinical data for cerebellar patients

\begin{tabular}{|c|c|c|c|c|c|c|c|c|c|c|c|c|c|}
\hline \multirow[b]{2}{*}{ Case } & \multirow[b]{2}{*}{ Age } & \multirow[b]{2}{*}{ Sex } & \multirow[b]{2}{*}{$\begin{array}{l}\text { Length of } \\
\text { Illness }\end{array}$} & \multirow[b]{2}{*}{ Diagnosis $^{a}$} & \multicolumn{2}{|c|}{ Tremor } & \multicolumn{2}{|c|}{ Ataxia } & \multirow[b]{2}{*}{ Dysarthia } & \multirow[b]{2}{*}{$\begin{array}{l}\text { Oculo- } \\
\text { motor }\end{array}$} & \multicolumn{2}{|c|}{ Tendon reflexes } & \multirow[b]{2}{*}{$\begin{array}{l}\text { Pathological } \\
\text { Reflexes }\end{array}$} \\
\hline & & & & & Arm & $\begin{array}{l}\text { Head/ } \\
\text { Trunk }\end{array}$ & Arm & $\begin{array}{l}\text { Stancel } \\
\text { Gait }\end{array}$ & & & $\begin{array}{l}\text { Upper } \\
\text { Limb }\end{array}$ & $\begin{array}{l}\text { Lower } \\
\text { Limb }\end{array}$ & \\
\hline $\begin{array}{l}\text { WD } \\
\text { RB } \\
\text { KS } \\
\text { EH } \\
\text { BR } \\
\text { HF } \\
\text { KB } \\
\text { VR } \\
\text { EZ }\end{array}$ & $\begin{array}{l}37 \\
55 \\
60 \\
47 \\
63 \\
57 \\
35 \\
54 \\
63\end{array}$ & $\begin{array}{l}M \\
F \\
M \\
M \\
M \\
M \\
M \\
M \\
M\end{array}$ & 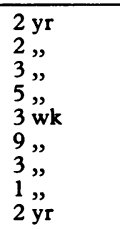 & $\begin{array}{c}\text { Degeneration } \\
\text { ", } \\
\text { "' } \\
\text { Infarcation } \\
\text { ", } \\
\text { ", } \\
\text { Metastasis }\end{array}$ & $\begin{array}{l}2^{\mathrm{b}} \\
0 \\
2 \\
2 \\
2 \\
0 \\
0 \\
0 \\
0\end{array}$ & $\begin{array}{l}2 \\
0 \\
3 \\
3 \\
0 \\
0 \\
0 \\
0 \\
0\end{array}$ & $\begin{array}{l}1 \\
2 \\
2 \\
2 \\
3 \\
2 \\
2 \\
0 \\
1\end{array}$ & $\begin{array}{l}3 \\
3 \\
2 \\
3 \\
2 \\
4 \\
0 \\
2 \\
2\end{array}$ & $\begin{array}{l}1 \\
2 \\
0 \\
2 \\
1 \\
0 \\
0 \\
0 \\
0\end{array}$ & $\begin{array}{l}1 \\
3 \\
0 \\
2 \\
4 \\
4 \\
0 \\
0 \\
1\end{array}$ & $\begin{array}{l}+ \\
++ \\
++ \\
+ \\
+ \\
+ \\
++ \\
+ \\
++\end{array}$ & $\begin{array}{l}++ \\
++ \\
++ \\
++ \\
+ \\
+ \\
++ \\
+ \\
++\end{array}$ & $\begin{array}{l}0 \\
0 \\
0 \\
3 \\
3 \\
3 \\
0 \\
1 \\
0\end{array}$ \\
\hline
\end{tabular}

'see text for detai'ed description of diagnosis

brating of clinical symptoms: $0=$ normal, $1-5=$ mild to severe disturbance. 
(180 deg equivalent to full extension). The targets were not mechanically detectable and were not bounded by mechanical stops. Position of the manipulandum handle was displayed as a thin vertical line.

Subjects were instructed to place the handle cursor within the target zone according to the given instruction. Instructions were: 1) "move accurately" with an emphasis on placing the handle cursor exactly in the middle of the target zone, 2) "move fast but accurately" with an emphasis on avoiding any overshoot of the target zone and 3) "move as fast as possible" where speed was stressed.

During each experimental session, the subject was asked to make a series of steptracking movements about the elbow. Each trial consisted of 30 flexion-extension movements. Target amplitude varied from $10^{\circ}$ to $70^{\circ}$ but was kept constant during any given trial. Accurate movements were performed first, followed by fast/accurate movements and finally movements made as fast as possible. Within each instruction block (for example, "accurate"), target amplitude varied randomly from trial to trial. The task was not a reaction time task in that the subject was not required to minimise movement onset time relative to movement of the target. Each subject was allowed 2-3 minutes of practice before data sampling. Recording sessions never exceeded one hour.

Data recording and analysis

Angular position and velocity of the manipulandum handle were recorded respectively from a potentiometer and tachometer mounted beneath the pivot point of the handle. Data were digitised on-line with an effective sampling rate of $250 \mathrm{~Hz}$. Each movement was analysed individually using automatic computer programmes. Timing points were determined from the differentiated velocity signal using an acceleration threshold of $120^{\circ} / \mathrm{s} 2$. End of movement was arbitrarily defined as that point where the subject was within $3^{\circ}$ of target centre. Using this definition, $5-10 \%$ of movements were considered not of the correct amplitude and were discarded. Computer selected timing points were later confirmed by visual inspection of plotted records. Statistical evaluation of group differences was determined using a two-tailed Student's $t$ test where appropriate.

\section{Results}

Interaction between peak velocity, movement duration and amplitude

All patients were able to perform reproducible, step-tracking movements after a short period of practice. Typical records of arm velocity associated with $70^{\circ}$ movements made as fast as possible are shown in fig 1 for a normal (A) and two cerebellar patients (B, C). Movements made by normal subjects were highly stereotyped with bell-shaped, symmetrical velocity profiles. The records in $B$ (cerebellar 1 , patient WD) were representative of movements made by most of the patients under investiga-
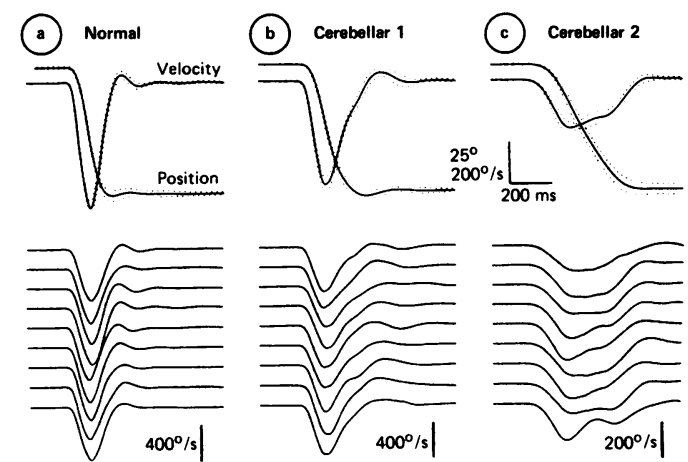

Figure 1 Kinematic profiles associated with $70^{\circ}$ flexion movements about the elbow. In the upper half of the figure are shown averaged $1 S D(n=12)$ position and velocity records obtained from a normal subject $(A-35 y \mathrm{r})$ and two cerebellar patients ( $B-37$ year (WD), $C-35$ year (KB)). Movements were made "as fast as possible" in response to a step change in target position. Individual velocity records comprising each average are plotted in the lower panel. Both averaged and individual records are aligned around movement onset. Individual velocity records in $C$ have been increased in scale for purposes of illustration.

tion: a smooth acceleratory phase followed by a slower, more prolonged period of deceleration. In $\mathrm{C}$ (cerebellar 2 , patient $\mathrm{KB}$ ) are shown velocity records obtained from the most severely affected patient. In this patient, individual movements were often characterised by either a secondary, low amplitude velocity peak or a period of relatively constant velocity. All patients were able to smoothly terminate each movement within the target zone and the degree of terminal overshoot in movements made as fast as possible was no greater in the patient than in the normal group. Flexion and extension movements were qualititatively similar and thus only data associated with flexion movements are presented.

Patients were able to modulate movement velocity in response to changes in either target amplitude or instruction. This is shown in fig 2. Peak velocity increased with increasing movement amplitude regardless of instruction. For a given movement amplitude, peak velocity depended on the patient's strategy or the instruction given ("accurate" versus "fast"). Movement duration also changed with both amplitude and instruction. Despite large

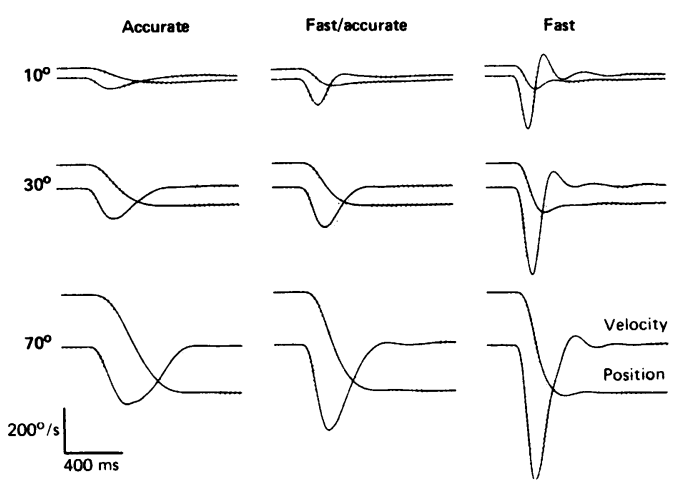

Figure 2 Changes in movement kinematics with amplitude and instruction. Averaged position and velocity $1 S D(n=12)$ records obtained from a 37 year old cerebellar patient (WD) are shown for 10, 30 and $70^{\circ}$ flexion movements under 3 instructions (Accurate, Fast/Accurate, Fast). All data have been aligned around movement onset. 


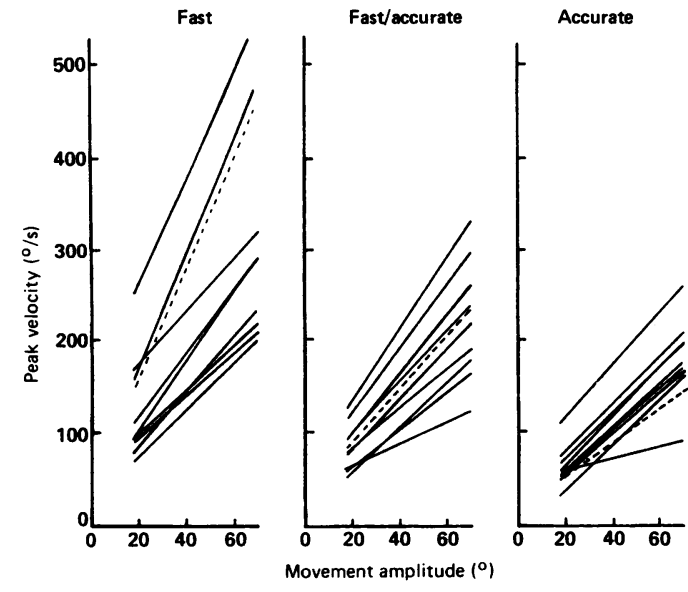

Figure 3 Amplitude dependent scaling of peak velocity. Individual linear regression lines are plotted for each patient under each instruction condition. Pooled data from normal subjects are represented by the dashed regression lines. Slope, intercept and correlation coefficient $(r)$ values for each patient are given in table 2.

differences in amplitude, duration and peak velocity across the range of movements examined, most patients produced movements with smooth, unimodal velocity profiles. As with normal subjects, terminal oscillations were only seen during movements made as fast as possible.

In all patients peak velocity increased linearly with movement amplitude. Best fit regression lines for each patient are shown in fig 3. Values of regression parameters given in table 2 indicate that the relationship was highly linear across subjects. Linear scaling of peak velocity with amplitude was preserved regardless of instruction. However, the gain (slope) of the relationship was instruction dependent, being higher for fast than for accurate movements. For moderate speed movements (fast/accurate), maximum velocity did not differ greatly from mean normal values. Movements made as rapidly as possible were, in general, slower in the cerebellar group,

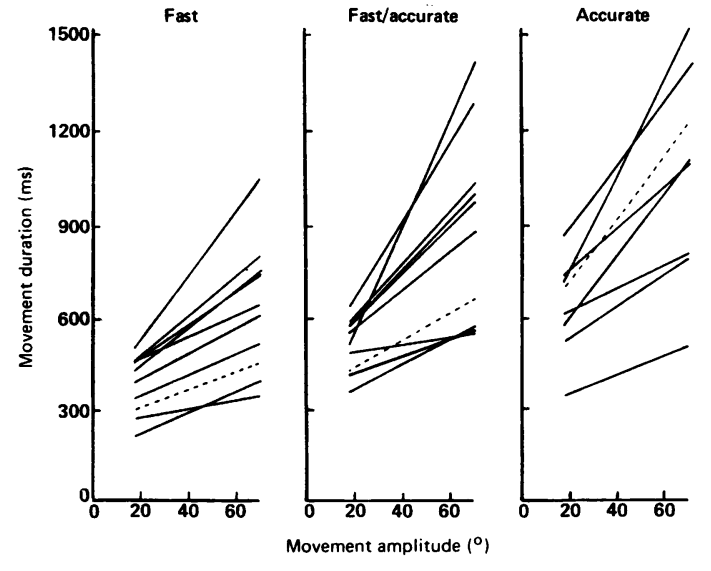

Figure 4 Changes in movement duration with amplitude. Individual linear regression lines are plotted for each patient under each instruction condition. Pooled data from normal subjects are represented by the dashed regression lines. Slope, intercept and correlation coefficient $(r)$ values for each patient are given in table 2.

particularly at larger movement amplitudes. Accurate movements greater than $20^{\circ}$ amplitude were performed at slightly higher speeds than that observed in the normal group.

As stated earlier, movement duration increased with amplitude. While this relationship was linear for each instruction in all patients with two exceptions (EZ-fast/ accurate; KS accurate), slope and intercept values were highly variable across patients (fig 4 , table 2). The time required for movement completion generally reflected the maximum speed attained during the movement (fig 3). Thus, compared to normal values, movement durations were slightly longer for fast movements and, on average, slightly shorter for accurate movements. For moderate speed (fast/ accurate) movements, however, movement duration tended to be longer in the cerebellar group despite peak velocities being within normal limits (fig 2).

To summarise, a highly linear relationship

Table 2 Summary of linear regression analysis

\begin{tabular}{|c|c|c|c|c|c|c|c|c|c|}
\hline Case & $\begin{array}{l}\text { Fast } \\
\text { intercept }\end{array}$ & slope & $r$ & $\begin{array}{l}\quad \text { Peak Velocit } \\
\text { Fast/Accurate } \\
\text { intercept }\end{array}$ & $\begin{array}{l}\text {-Amplitude } \\
\text { slope }\end{array}$ & $r$ & $\begin{array}{l}\text { Accurate } \\
\text { intercept }\end{array}$ & slope & $r$ \\
\hline $\begin{array}{l}\text { WD } \\
\text { RB } \\
\text { KS } \\
\text { EH } \\
\text { RB } \\
\text { HF } \\
\text { KB } \\
\text { VR } \\
\text { EZ } \\
\text { norm }^{\text {b }}\end{array}$ & $\begin{array}{r}154 \\
27 \\
49 \\
28 \\
46 \\
29 \\
54 \\
117 \\
49 \\
36\end{array}$ & $\begin{array}{l}5 \cdot 6 \\
2 \cdot 9 \\
3 \cdot 4 \\
2 \cdot 4 \\
2 \cdot 5 \\
3 \cdot 8 \\
2 \cdot 2 \\
2 \cdot 9 \\
6 \cdot 2 \\
6 \cdot 2\end{array}$ & $\begin{array}{l}0.96 \\
0.99 \\
0.98 \\
0.89 \\
0.94 \\
0.96 \\
0.98 \\
0.86 \\
1.00 \\
0.99\end{array}$ & $\begin{array}{l}50 \\
71 \\
30 \\
13 \\
28 \\
34 \\
40 \\
43 \\
46 \\
24\end{array}$ & $\begin{array}{l}4 \cdot 1 \\
1.5 \\
2.7 \\
2 \cdot 4 \\
1.9 \\
3 \cdot 2 \\
1.2 \\
2.8 \\
3.7 \\
2.9\end{array}$ & $\begin{array}{l}0.98 \\
0.88 \\
0.96 \\
0.97 \\
0.98 \\
0.98 \\
0.81 \\
0.99 \\
0.99 \\
0.99\end{array}$ & $\begin{array}{r}22 \\
12 \\
24 \\
-17 \\
12 \\
13 \\
47 \\
-4 \\
61 \\
17\end{array}$ & $\begin{array}{l}2 \cdot 7 \\
2 \cdot 6 \\
2 \cdot 4 \\
2 \cdot 6 \\
2 \cdot 2 \\
2 \cdot 2 \\
0.6 \\
\frac{2.9}{1 \cdot 8}\end{array}$ & $\begin{array}{l}0.97 \\
1.00 \\
1.00 \\
0.98 \\
1.00 \\
1.00 \\
0.92 \\
- \\
0.89 \\
0.98\end{array}$ \\
\hline
\end{tabular}

\begin{tabular}{|c|c|c|c|c|c|c|c|c|c|}
\hline Case & $\begin{array}{l}\text { Fast } \\
\text { intercept }\end{array}$ & slope & $r$ & $\begin{array}{l}\text { Movement Dur } \\
\text { Fast/Accurate } \\
\text { intercept }\end{array}$ & $\begin{array}{l}\text { tion- } \\
\text { slope }\end{array}$ & $r$ & $\begin{array}{l}\text { Accurate } \\
\text { intercept }\end{array}$ & slope & $r$ \\
\hline $\begin{array}{l}\text { WD } \\
\text { RB } \\
\text { KS } \\
\text { EH } \\
\text { BR } \\
\text { HF } \\
\text { KB } \\
\text { VR } \\
\text { EZ } \\
\text { norm }^{b}\end{array}$ & $\begin{array}{l}153 \\
355 \\
320 \\
335 \\
401 \\
367 \\
329 \\
273 \\
246 \\
250\end{array}$ & $\begin{array}{r}3.5 \\
6.4 \\
4.2 \\
10.4 \\
5.0 \\
5.5 \\
6.3 \\
3.5 \\
1.5 \\
3.1\end{array}$ & $\begin{array}{l}0.90 \\
0.92 \\
0.86 \\
0.99 \\
0.98 \\
1.00 \\
0.74 \\
0.98 \\
0.99 \\
0.96\end{array}$ & $\begin{array}{l}289 \\
442 \\
444 \\
454 \\
420 \\
428 \\
226 \\
356 \\
471 \\
354\end{array}$ & $\begin{array}{r}4 \cdot 0 \\
8 \cdot 4 \\
6 \cdot 1 \\
7 \cdot 5 \\
12 \cdot 2 \\
8 \cdot 4 \\
16 \cdot 8 \\
3 \cdot 0 \\
1 \cdot 1 \\
4 \cdot 5\end{array}$ & $\begin{array}{l}0.94 \\
0.96 \\
0.97 \\
0.95 \\
0.99 \\
0.93 \\
1.00 \\
1.00 \\
0.42 \\
0.92\end{array}$ & $\begin{array}{l}438 \\
400 \\
566 \\
637 \\
457 \\
697 \\
280 \\
525\end{array}$ & $\begin{array}{r}5.0 \\
9.9 \\
3.5 \\
6.5 \\
15.1 \\
9.9 \\
3.3 \\
10.0\end{array}$ & $\begin{array}{l}0.86 \\
0.95 \\
0.56 \\
\overline{0.99} \\
0.92 \\
0.98 \\
0.79 \\
0.96\end{array}$ \\
\hline
\end{tabular}

data unavailable

mean regression values for normal subjects

movements too slow for on-line sampling time 


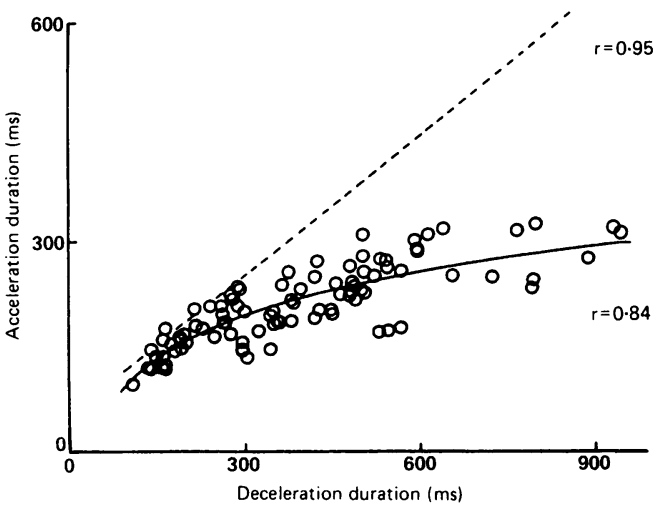

Figure 5 Relationship between acceleration duration and deceleration duration. Duration values obtained from all patients are shown. Each averaged $(n=12)$ data point represent movements made by an individual patient at a given movement amplitude and under a given instruction. Correlation coefficient of 0.84 corresponds to a best-fit logarithmic regression line. Dashed linear regression line $(r=0.95)$ represents pooled data $(n=66)$ from normal subjects.

between peak velocity and 'movement amplitude was preserved in patients with mild cerebellar symptoms with the slope of the relationship instruction dependent. A similar relationship between movement duration and amplitude occurred but was more variable across subjects.

\section{Acceleration duration/deceleration duration relationship}

Despite relatively normal scaling of peak velocity with amplitude, movements made by cerebellar patients were asymmetric in their time course (fig $1 \mathrm{~B}, \mathrm{C}$; fig 2 accurate and fast/ accurate). This is illustrated in fig 5 where data have been plotted for all patients, amplitudes and instructions. Each data point is the mean value for an individual patient performing movements of a particular amplitude and instruction. For relatively short duration $(<500$ ms) movements, acceleration and deceleration durations were approximately equal and close

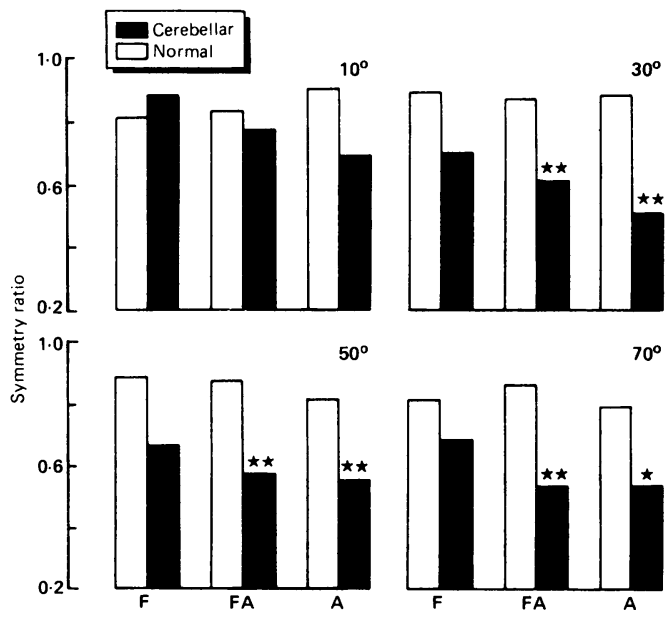

Figure 6 Changes in the ratio of acceleration duration to deceleration duration (symmetry ratio) as a function of amplitude and instruction. In each histogram mean symmetry ratios for normal subjects are plotted (open bars) and cerebellar patients (solid bars). Data are given for each instruction ( $F=$ fast; $F A=$ fast/accurate; $A=$ accurate) at each movement amplitude $(10,30,50$ $70 \mathrm{deg})$. Asterisks indicate level of significant difference between groups as determined by a two-tailed Student's $t$ test analysis $\left.{ }^{\star}=p \leqslant 0.01, \star \star=p \leqslant 0.005\right)$. to the mean normal curve (dashed line). However, as total movement duration increased in the patients, deceleration duration became disproportionately longer compared to acceleration duration. In normal subjects, acceleration duration was graded up to approximately $500 \mathrm{~ms}$ while, in contrast, none of the patients exhibited movements with acceleration durations greater than $300 \mathrm{~ms}$. As a result, the relationship between acceleration duration and deceleration duration was well described by a logarithmic function which gave a slightly better goodness of fit $(r=0.84)$ than did a linear function $(r=0.78)$.

The degree of movement asymmetry, determined by the ratio of acceleration duration to deceleration duration (symmetry ratio $=S R$ ), appeared to be both amplitude and instruction dependent. Figure 6 shows that medium to large amplitude movements $\left(30-70^{\circ}\right)$ were consistently characterised by skewed velocity profiles and that slower (accurate) movements were more asymmetric than movements made as fast as possible. In contrast, the time course of $10^{\circ}$ movements was not significantly different from normal values regardless of instruction. This was also true for all movements made as fast as possible independent of movement amplitude. Movements made by normal subjects were nearly symmetric in their time course at all amplitudes and under all instructions (SR range: $0.8-0.9$; mean $\mathrm{SR}=0.85$ ).

To determine if the asymmetry in movement profiles was best correlated with total movement duration as suggested in fig 5 and 6 or with peak velocity (since, for example, longer duration movements were associated with lower speeds), movement duration and peak velocity were plotted separately as a function of SR. This is shown in fig 7. As can be seen in A, the degree of skewness was clearly dependent on movement duration. Only at movement durations of less than $500 \mathrm{~ms}$ did SR values approach the normal range (fig 6). As movement duration increased, SR decreased to values in which deceleration duration was twice as long as acceleration duration (SR $<0.5$ ). The relationship between movement duration and SR was highly correlated and best described by an exponential function $(r=0 \cdot 82)$.

Surprisingly, the degree of movement asymmetry was not affected by the maximum speed of the movement (fig 7B). Movements with low $S R$ values $(<0.5)$ and thus highly asymmetric were associated with a broad range of maximum velocities as was also the case for relatively symmetric movements ( $\mathrm{SR} \geqslant 0.8$ ). Therefore, in movements in which both speed and duration increase, the resulting velocity skewness appears to be a result of the increase in total movement duration rather than the associated increase in peak velocity.

\section{Changes in movement variability}

In addition to being temporally asymmetric, movements made by cerebellar patients were, in general, more variable than normal subjects (fig 8). Although mean values were consistently greater in the cerebellar group regardless of 

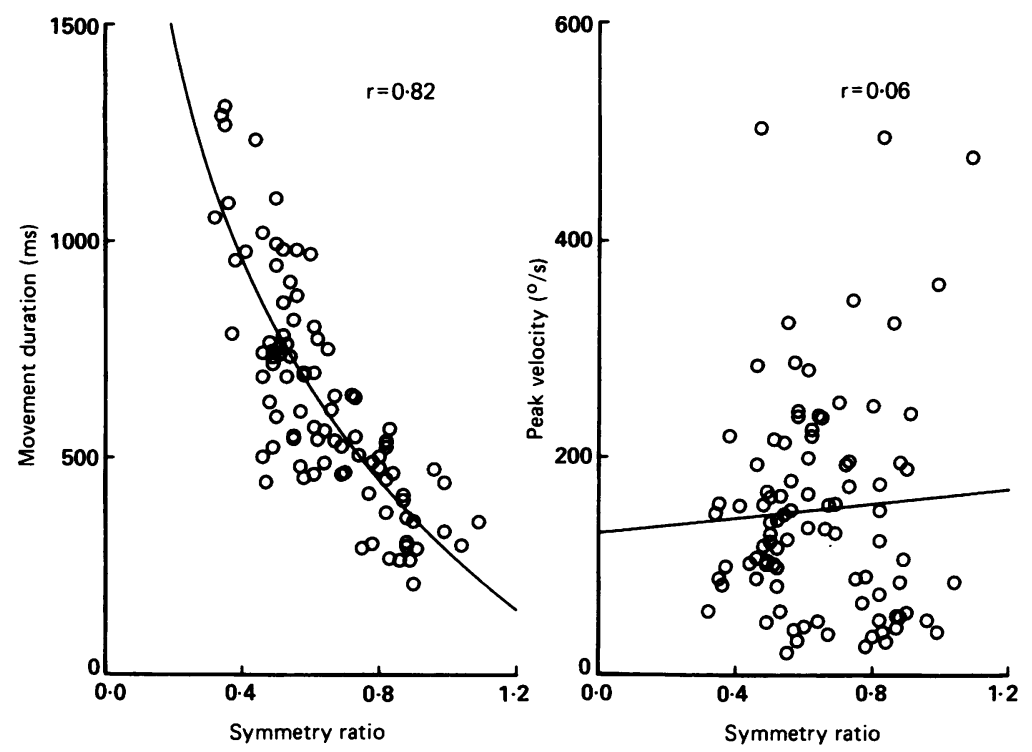

Figure 7 Effect of movement duration and peak velocity on symmetry ratio. Each graph shows data obtained from all patients. Each averaged $(n=12)$ data point corresponds to movements made by an individual patient at a given amplitude and instruction. The relationship between movement duration and symmetry ratio was best described by an exponential function $(r=0.82)$. No significant effect of peak velocity on symmetry ratio could be determined.

instruction or amplitude, significant differences occurred primarily in the fast/accurate condition. The degree of movement variability thus appeared to be task specific in that the demand for both speed and accuracy resulted in more variability than when only speed or accuracy was emphasised. No clear effect of movement amplitude on variability could be discerned. Variability in peak velocity, however, was consistently greater in small movements $\left(10^{\circ}\right)$, particularly for movements made as fast as possible and those made fast and accurately.
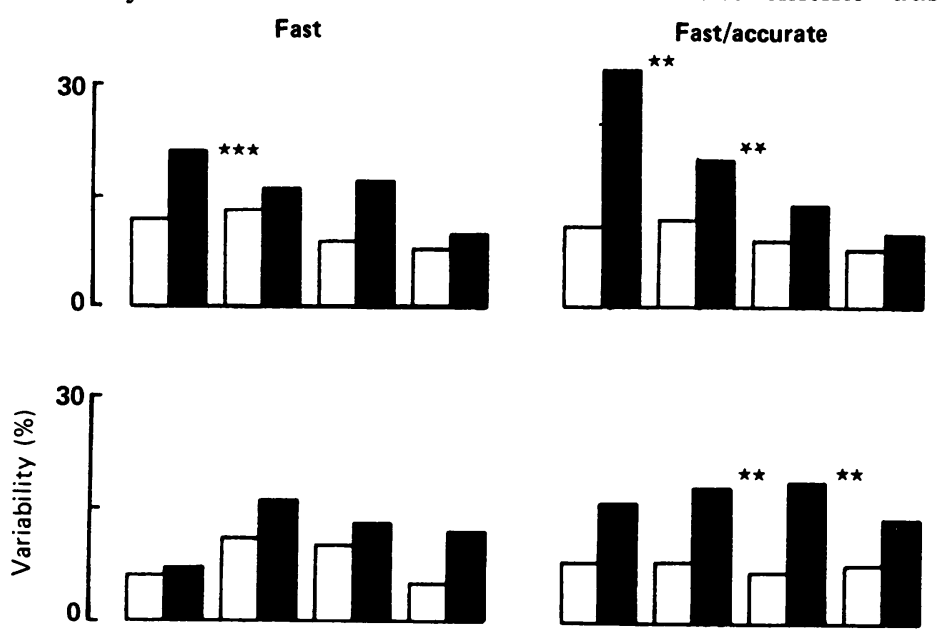

During the planning of either simple, singlejoint or more complex, multi-joint movements, the central nervous system is concerned with two problems: 1) where to move and 2) how to move. In the first case, changes in the relative levels of tonic muscle activity acting about a given joint are sufficient to move the limb to a new position as long as the demand for speed does not exceed limitations imposed by viscoelastic forces. ${ }^{2829}$ Movements produced in such a manner are generally too slow to meet task requirements, however, and thus how one moves becomes a central factor in determining the appropriate motor output. The results of this study show that, while patients with mild cerebellar dysfunction of the upper extremities can move successfully to externally determined target positions. the time course of the movement is disturbed. Moreover, these changes in movement trajectory are not simply due to alterations in or between specific movement parameters such as maximum speed or amplitude but appear to result from inadequate scaling of acceleration duration.

It is well known that, in normal subjects, the relationship between maximum speed and amplitude is highly linear. ${ }^{14-16}$ The slope of the relation is dependent on instructional set, being greater for movements made as fast as possible than for movements made accurately. ${ }^{15}$ The results presented here show that cerebellar patients were also capable of scaling peak velocity over a seven-fold increase in amplitude and that linearity between these two parameters was independent of speed and/or accuracy demands. Amplitude dependent increases in movement speed have also been described for slow, continuous tracking movements during cooling of the dentate Fast/accurate Accurate

Peak velocity

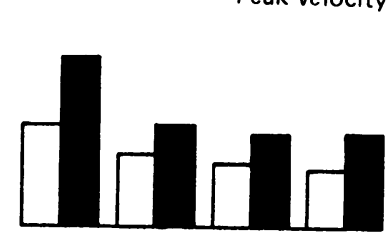

Movement duration
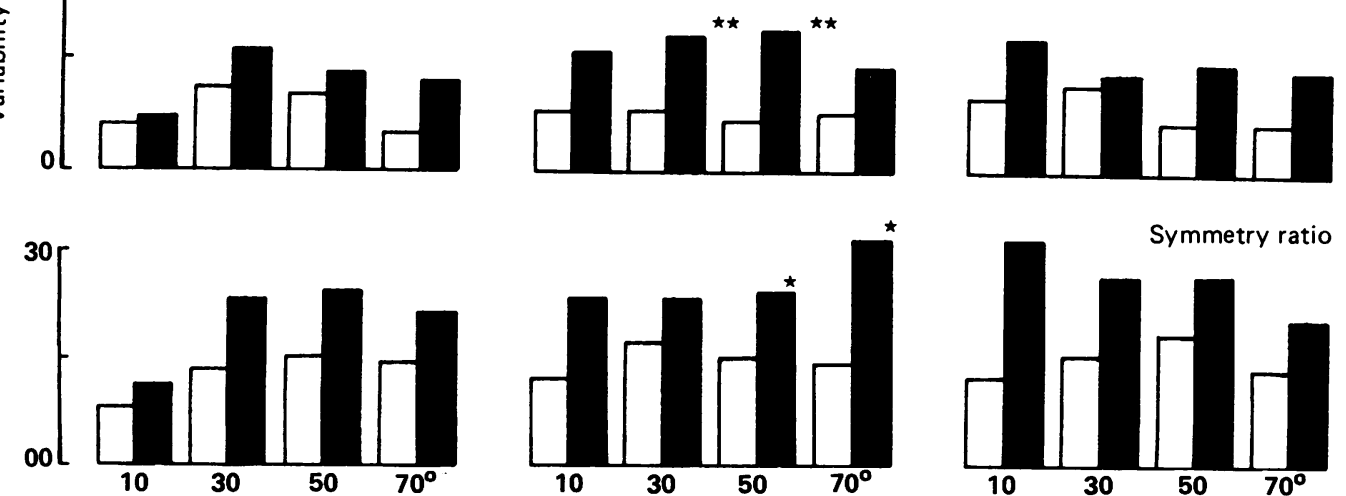

Figure 8 Variability of peak velocity, movement duration and symmetry ratio. Coefficient of variation values for normals (open bars) and cerebellar patients (solid bars) are plotted for each kinematic variable as a function of amplitude and instruction. Asterisks indicate level of significant difference between groups as determined by a two-tailed Student's $t$ test analysis $\left.{ }^{\star}=p \leqslant 0.05 ; \star \star=p \leqslant 0.01 ; \star \star \star=p \leqslant 0.005\right)$. 
nucleus in primates ${ }^{12}$ and for rapid wrist movements in Parkinson patients. ${ }^{30}$ Taken together, these findings suggest that the relationship between peak velocity and amplitude is relatively immune to disruption of either the cerebellum or basal ganglia.

Not surprisingly, movements made as fast as possible were slower in the cerebellar group compared to normals. As the demand for accuracy increased, differences in peak velocity were minimal. It must be noted, however, that the $\pm 3^{\circ}$ error allowed for final position may not have been stringent enough to force a significant slowing of movement velocity in the cerebellar group.

Miall et al $^{12}$ have recently suggested that the cerebellum may act to finely tune movements by limiting peak velocity. In this study, accurate movements were associated with slightly higher peak velocities compared to normal values. These movements, however, were still performed smoothly and with the required degree of accuracy and thus it is most likely that any increase in speed simply reflects differences in the subjective interpretation of the instruction. Development of more "ballistic" and less accurate movements which has been reported for continuous, pursuit tracking following dentate inactivation in primates ${ }^{12}$ and in cerebellar patients performing similar tracking tasks ${ }^{1113}$ may be explained both by differences in the severity of the lesion and the type of tracking task employed. In the first case, we chose to examine patients with mild disturbances of the upper limbs. It is therefore possible that any inability to properly adjust maximum speeds during step tracking movements is not observed in the early stages of cerebellar dysfunction.

Secondly, there is growing evidence to suggest that afferent information plays a greater role in the generation of slow, pursuit tracking movements than, for example, more rapid, step tracking movements where only start and end positions are determined. ${ }^{31-34}$ Schieber and Thach ${ }^{35}$ have hypothesised that the cerebellum may act to regulate muscle spindle sensitivity via independent control of the fusimotor system. Thus, by presetting spindle sensitivity, the cerebellum could optimise afferent feedback which would be of particular value during slow tracking requiring constant monitoring of performance errors.

Although the relationships between peak velocity, movement duration and amplitude were preserved in cerebellar patients, the moment to moment time course was found to be disturbed. Specifically, this alteration in movement dynamics took the form of skewed velocity profiles. In normal subjects, movements exhibit temporally symmetric velocity profiles where the time spent in accelerating and decelerating the limb are approximately equal. Symmetrical profiles have been described for elbow and speech movements ${ }^{19}$ as well as movements of the vocal folds. ${ }^{36}$ More complex movements such as those involved in reaching are also symmetrical when made in either the horizontal ${ }^{18}$ or vertical $^{17}$ planes and under different load con- ditions. ${ }^{3738}$

Together, these observations have lent support to the hypothesis that movement trajectory is centrally determined and may reflect a basic organising principle underlying movement generation. ${ }^{162039}$ Mathematical modelling has shown that time symmetric profiles can result from minimising the rate of change of acceleration to produce movements in the most energy efficient manner. ${ }^{20} 39$ Thus, movements of different amplitudes, for example, might be produced by a relatively simple scaling of a base trajectory profile.

In our study, movements made by cerebellar patients, regardless of pathology, were consistently characterised by short acceleration and long deceleration phases. This asymmetry in movement profile was independent of peak velocity but covaried with movement duration. Thus, large amplitude movements made slowly and accurately exhibited a marked asymmetry while rapid, small amplitude movements were, in fact, slightly more symmetric than normals.

Why cerebellar patients perform step tracking movements with temporally asymmetric profiles is not clear. One partial explanation may lie in the observation that, despite total movement durations of over $1 \mathrm{~s}$, the duration of the acceleratory phase never exceeded $300 \mathrm{~ms}$. Recent experiments in normal subjects have clearly demonstrated that the temporal structure of movements depends upon the precise timing of phasic drive to opposing muscle groups. ${ }^{23}$ For example, shifts in velocity profiles from short to long acceleration durations while maintaining total movement duration constant are accomplished by an increase in the duration of the initial agonist burst. Additional studies have shown that the duration of this burst is directly related to the duration of the acceleratory phase, independent of changes in mean acceleration. ${ }^{40}$ Thus, in our study, it is likely that the duration of the initial agonist burst was not continuously graded as movement duration increased. This would, in turn, result in movements with short acceleration durations and skewed velocity profiles.

The finding that cerebellar patients appeared unable to appropriately scale acceleration duration contrasts with other studies in which cerebellar dysfunction led to a prolongation of acceleration duration. Flament and Hore $^{5}$ found, for example, that inactivation of the dentate nucleus in monkeys resulted in prolonged accelerations which were associated with an increase in initial agonist burst duration as well as a delay in onset of antagonist activity. Increased initial agonist burst duration has also been described for cerebellar patients during fast elbow flexion movements ${ }^{9}$ but accompanying alterations in movement kinematics were not reported. Although appropriate modulation of initial agonist burst duration may have been affected in the present study, it can be inferred from the patients' ability to increase peak velocity with amplitude that control of burst magnitude was not disturbed, or at least not to the same extent as with duration.

It cannot be assumed, a priori, that altera- 
tions in movement symmetry seen here necessarily result from an inability to adjust the timing of early EMG activity associated with movement initiation. It is possible, for example, that patients chose a strategy characterised by short accelerations and long decelerations to minimise terminal oscillations and maintain relatively smooth trajectories during the deceleratory phase. In this case, programming movements with short accelerations, independent of total movement duration, may serve to circumvent "active" control of deceleration, a process recently shown to involve the precise timing of both the antagonist and the second agonist bursts. ${ }^{41}$ On the other hand, patients had little difficulty producing time-symmetric, fast movements of short duration with, presumably, a triphasic EMG pattern.

An inability to programme "optimal reference trajectories", 42 that is, time-symmetric profiles may reflect changes at the motor planning level, possibily via cerebellothalamic facilitation of precentral neuronal discharge patterns. ${ }^{43}$ This does not mean, however, that deficits in cerebellar updating of the ongoing movement are not involved as well.

In conclusion, the ability to utilise a common, temporal profile across movements of different amplitudes and speeds appears to be compromised in cerebellar patients. Whether the production of asymmetric trajectories is due solely to disturbances in the proper timing of phasic muscle activity or also involves task dependent changes in movement strategy remains to be determined.

The authors are grateful to Dr JD Cooke for his helpful comments in the preparation of this manuscript. This work was supported by an Alexander von Humboldt Fellowship to SHB and grants from the Deutsche Forschungsgemeinschaft (SFB 200, B3). Preliminary findings were presented at the Society for Neuroscience meeting, Toronto, 1988.

1 Holmes G, The symptoms of acute cerebellar injuries due to gunshot injuries. Brain 1917;40:461-535.

2 Holmes $G$. The cerebellum of man. The Hughlings Jackson Memorial Lecture. Brain 1939;62:1-30.

3 Kornhuber $\mathrm{HH}$. Motor functions of cerebellum and basal ganglia: The cerebellocortical saccadic (ballistic) clock, the cerebellonuclear hold regulator, and the basal ganglia (voluntary speed smooth movement) generator. Kybernetik 1971;8:157-62.

4 Brooks VB, Kozlovskaya IB, Atkin A, Horvath FE, Uno M. Effects of cooling dentate nucleus on tracking-task performance in monkeys. $J$ Neurophysiol 1973;36:974-95.

5 Flament D, Hore J. Movement and electromyographic disorders associated with cerebellar dysmetria. J Neurophysiol 1986;55:1221-33.

6 Lamarre Y, Jacks B. Involvement of the cerebellum in the initiation of fast ballistic movements in the monkey. initiation of fast ballistic movements in the monkey.
Electroencephalogr Clin Neurophysiol Suppl 1978;34:4417 .

7 Meyer-Lohmann J, Hore J, Brooks VB. Cerebellar participation in generation of prompt arm movements. $J$ Neurophysiol 1977;40:1038-50.

8 Marsden CD, Merton PA, Morton HB, Hallett M, Adam J, Rushton DN. Disorders of movement in cerebellar disease in man. In: Rose, FC The Physiological Aspects of Clinical Neurology. Blackwell, Oxford, 1977:179-99.

9 Hallett M, Shahani BT, Young RR. EMG analysis of patients with cerebellar deficits. J Neurol Neurosurg Psychiatry 1975;38:1163-9.

10 Mai N, Bolsinger P, Avarello M, Diener HC, Dischgans J. Control of isometric finger force in patients with cerebellar disease. Brain 1988;111:973-98.

11 Beppu H, Suda M, Tanaka R. Analysis of cerebellar motor disorders by visually guided elbow tracking movements. Brain 1984;107:787-809.

12 Miall RC, Weir DJ, Stein JF. Visuo-motor tracking during reversible inactivation of the cerebellum. Exp Brain Res 987:65:455-4.

13 Miller RG, Freund HJ. Cerebellar dyssynergia in humansa quantitative analysis. Ann Neurol 1980;8:574-9.

14 Bouisset $S$, Lestienne $F$. The organization of a simple voluntary movement as analysed from its kinematic properties. Brain Res 1974;71:451-7.

15 Brown SH, Cooke JD. Amplitude and instruction-dependent modulation of movement-related electromyogram activity in humans. $J$ Physiol 1981;316:97-107.

16 Cooke JD. The organization of simple, skilled movements. Behavior. North Holland: Amsterdam 1980:199-212.

17 Atkeson CG, Hollerbach JM. Kinematic features of unrestrained vertical arm movements. J Neurosci 1985;5:231830.

18 Hollerbach JM, Flash T. Dynamic interactions between limb segments during planar arm movements. Biol Cybern 1982;44:67-77.

19 Ostry DJ, Cooke JD, Munhall KG. Velocity curves of human arm and speech movements. Exp Brain Res 1987;68:37-46.

$20 \mathrm{Hogan}$ N. An organizing principle for a class of voluntary movements. $J$ Neurosci 1984;4:2745-54.

21 Hallett $M$, Marsden $C D$. Ballistic flexion movements of the human thumb. J Physiol 1979;294:33-50.

22 Mustard BE, Lee RG. Relationship between EMG patterns and kinematic properties for flexion movements at the human wrist. Exp Brain Res 1987;66:247-56.

23 Brown SH, Cooke JD. Movement-related phasic muscle activation: I. Relations with temporal profile of movement. $J$ Neurophysiol 1990;63 (in press).

24 Braitenburg V. Is the cerebellar cortex a biological clock in the millisecond range? Prog Brain Res 1967;25:334-46.

25 Ivry RB, Keele SW, Diener HC. Dissociation of the lateral and medial cerebellum in movement timing and movement execution. Exp Brain Res 1988;73:167-80.

26 Cooke JD, Brown SH, Cunningham DA. Kinematics of arm movements in elderly humans. Neurobiol Aging 1989;10:159-66.

27 Harding AE. The Hereditary Ataxias and Related Disorders. Edinburgh: Churchill Livingstone 1984:166-73.

28 Bizzi E, Polit A, Morasso P. Mechanisms underlying achievement of final head position. J Neurophysiol 1976;39:435-44.

29 Fel'dman AG. Change in the length of the muscle as a consequence of a shift in equilibrium in the muscle-load system. Biophysics 1974;19:544-8.

30 Berardelli A, Rothwell JC, Day BL, Kachi T, Marsden CD. Duration of the first agonist EMG burst in ballistic arm movements. Brain Res 1984;304:183-7.

31 Freund HJ. Time control of hand movements. Prog Brain Res 1986;64:287-94.

32 Hulliger M, Nordh E, Vallbo AB. Discharge of muscle spindle afferents related to direction of slow precision movements in man. $J$ Physiol 1985;362:437-53.

33 Rothwell JC, Truab MM, Day BL, Obeso JA, Thomas PK, Marsden CD. Manual motor performance in a deafferented man. Brain 1982;105:515-42.

34 Sanes JN, Evarts EV. Effects of perturbations on accuracy of arm movements. $J$ Neurosci 1983;3:977-86.

35 Schieber MH, Thach WT. Trained slow tracking II Bidirectional discharge patterns of cerebellar nuclear, motor cortex and spindle afferent neurons. J Neurophysiol 1985;54:1228-70.

36 Munhall KG, Ostry DJ, Parush A. Characteristics of velocity profiles of speech movements. J Exp Psycho (Hum Percept) 1985;11:457-74.

37 Ruitenbeek JC. Invariance in loaded, goal directed movements. Biol Cybern 1985;51:11-20.

38 Soechting JF. Effect of target size on spatial and temporal characteristics of a pointing movement in man. Exp Brain Res 1984;54:122-32.

39 Nelson WL. Physical principles for economies of skilled movements. Biol Cybern 1983;46:135-47.

40 Brown SH, Cooke JD. Initiation of human arm movements: The initial agonist burst is related to movement acceleraThe initial agonist burst is rel
tion. IBRO Proc 1987;2:2473.

41 Cooke JD, Brown SH. Movement-related phasic muscle activation: II. Generation and functional role of the "triphasic" pattern. J Neurophysiol 1990;63 (in press).

42 Brooks VB. The Neurological Basis of Motor Control. Oxford Univ Press: New York 1986:256-89.

3 Brooks VB, Thach WT. Cerebellar control of posture and movement. In: Handbook of Physiology. The Nervous System-Motor Control Vol II. Am Physiol Soc: Bethesda 1981:877-946. 